\title{
Hospitalization budget impact during the COVID-19 pandemic in Spain
}

\author{
F. J. Carrera-Hueso ${ }^{1}$ (D) L. Álvarez-Arroyo ${ }^{1,2^{*}}$ (D) J. E. Poquet-Jornet ${ }^{3}$ (D) P. Vázquez-Ferreiro ${ }^{4}$ (D) \\ R. Martínez-Gonzalbez ${ }^{5}$ (D, D. El-Qutob ${ }^{6}$ (D) M. A. Ramón-Barrios ${ }^{7}$ (D) F. Martínez-Martínez ${ }^{8}$, J. L. Poveda-Andrés ${ }^{9}$ and \\ C. Crespo-Palomo ${ }^{10,11}$
}

\begin{abstract}
Objectives: The aim was to determine the direct impact of the COVID-19 pandemic on Spain's health budget.

Methods: Budget impact analyses based on retrospective data from patients with suspected severe acute respiratory syndrome coronavirus 2 (SARS-CoV-2) admitted to a Spanish hospital between February 26 and May 21, 2020. Direct medical costs from the perspective of the hospital were calculated. We analyzed diagnostic tests, drugs, medical and nursing care, and isolation ward and ICU stays for three cohorts: patients seen in the emergency room only, hospitalized patients who tested positive for SARS-CoV-2, and patients who tested negative.

Results: The impact on the hospital's budget for the 3 months was calculated at $€ 15,633,180,97.4 \%$ of which was related to health care and hospitalization. ICU stays accounted for $5.3 \%$ of the total costs. The mean cost per patient was $€ 10,744$. The main costs were staffing costs $(10,131$ to $11,357 € /$ patient for physicians and 10,274 to $11,215 € /$ patient for nurses). Scenario analysis showed that the range of hospital expenditure was between $€ 14,693,256$ and $€ 16,524,924$. The median impact of the pandemic on the Spanish health budget in the sensitivity analysis using bootstrapped individual data was $€ 9357$ million (interquartile range [IQR], 9071 to 9689) for the conservative scenario (113,588 hospital admissions and 11,664 ICU admissions) and €10,385 million (IQR, 110,030 to 10,758) for the worst-case scenario (including suspected cases).
\end{abstract}

Conclusion: The impact of COVID-19 on the Spanish public health budget (12.3\% of total public health expenditure) is greater than multiple sclerosis, cancer and diabetes cost.

Keywords: Costs and cost analysis, COVID-19, Health care costs, Clinical laboratory tests, Hospitalization, Budgets

\section{Introduction}

Coronavirus disease 2019 (COVID-19), caused by severe acute respiratory syndrome coronavirus 2 (SARS-CoV2), was declared a pandemic by the World Health Organization. By the end of June, it had affected 188 countries, with over 9 million confirmed cases and rising infection rates [1]. A variety of public health measures

\footnotetext{
* Correspondence: lauraalvarez6@yahoo.es

${ }^{1}$ Pharmacy Service, University Hospital La Plana, Carretera de Vila-real a Burriana, Km. 0.5, 12540 Villarreal, Castellón, Spain

${ }^{2}$ Pharmacy Doctoral Program at University of Granada, Granada, Spain Full list of author information is available at the end of the article
}

have been adopted to control the pandemic and ease the burden on healthcare systems [2].

The long-term health consequences and potential sequelae of COVID-19 are unknown [3, 4], but the social and economic impacts are already worse than those of the Second World War [3]. While major COVID-19related research efforts are underway, there is a paucity of studies examining the impacts of the pandemic on public health budgets. This information is crucial to correctly manage the ongoing crisis, prepare for second waves [5], and guide the implementation and management of new services such as telemedicine or the

C C The Author(s). 2021 Open Access This article is licensed under a Creative Commons Attribution 4.0 International License, which permits use, sharing, adaptation, distribution and reproduction in any medium or format, as long as you give appropriate credit to the original author(s) and the source, provide a link to the Creative Commons licence, and indicate if changes were made. The images or other third party material in this article are included in the article's Creative Commons licence, unless indicated otherwise in a credit line to the material. If material is not included in the article's Creative Commons licence and your intended use is not permitted by statutory regulation or exceeds the permitted use, you will need to obtain permission directly from the copyright holder. To view a copy of this licence, visit http://creativecommons.org/licenses/by/4.0/ The Creative Commons Public Domain Dedication waiver (http://creativecommons.org/publicdomain/zero/1.0/) applies to the data made available in this article, unless otherwise stated in a credit line to the data. 
creation of dedicated COVID-19 clinic units. Budget information is also needed to establish interventionspecific costs and is essential for analyzing the costeffectiveness of new treatments for COVID-19. It can also help identify diagnostic groups that should allow for improved management.

The aim of this study was to conduct a hospital budget impact analysis to assess the impact of COVID-19 at its peak on the Spanish public health budget.

\section{Methods}

\section{Study design, population, and resources}

We estimated the impact of COVID-19, considering all direct medical costs, on the Spanish public health budget by extrapolating data from a retrospective cohort study covering a period of 86 days during the peak of the pandemic. The study was conducted in a 252-bed Spanish hospital that serves a catchment area of 187,258 people. It was registered with the Spanish Agency of Medicines and Medical Products (AEMPS) and approved by the hospital's ethics committee. Verbal informed consent in the presence of a witness was obtained from all patients and noted in the patients' medical records. This procedure was authorized by the Spanish Health authorities in view of the exceptional epidemiological situation. Eligible patients were adults ( $>18$ years) with suspected COVID-19 who visited the hospital's emergency room (ER) between February 26 and May 21, 2020. Pregnant women were excluded. In cases of readmission, data from the first admission only were analyzed.

The patients were classified into three cohorts: 1) those not requiring hospital admission (ER cohort), 2) those admitted to the hospital and who received a positive real-time polymerase chain reaction (RT-PCR) result within $24 \mathrm{~h}$ (SARS-CoV-2-positive cohort), and 3) those admitted to the hospital and who received a negative RT-PCR result within $24 \mathrm{~h}$ (SARS-CoV-2-negative cohort).

Individual records of all patients in the ER cohort were reviewed to identify the tests performed (RT-PCR, chest $\mathrm{X}$-ray, and blood tests [complete blood count, biochemical parameters, coagulation test]. A record was also made of time spent in the ER for all patients. Stays of $16 \mathrm{~h}$ or less were classified as medical visits, while longer stays were classified as ER stays.

Individual information was also collected on all tests performed during hospitalization. These included RTPCR, imaging studies, blood tests [complete blood count, biochemical parameters, coagulation test], blood gas analysis, other laboratory tests (ferritin, D-dimer, Creactive protein, and procalcitonin), and microbiological tests (blood cultures and testing for multiple atypical respiratory pathogens). We also calculated lengths of intensive care unit stays (ICU stays) and isolation ward stays (general stays). For the SARS-CoV-2-negative cohort, we calculated resources used in the first $48 \mathrm{~h}$ of hospitalization, as this was the maximum time for receiving RT-PCR results. We also analyzed survival at the end of follow-up for SARS-CoV-2-positive and -negative cohorts.

\section{Costs}

Direct medical costs from the perspective of the hospital were calculated in 2020 Euros $(€)$. Discounts and indirect or intangible costs were not considered. Unit costs for ER and ICU stays, hospitalization, and staff salaries were obtained from the official rates established for our hospital for 2020 and checked against rates for several hospitals in different regions of Spain [6]. These were then multiplied by resource use data for each cohort to provide a combined total. Drug prices were obtained from the hospital's pharmacy department. The main drug groups considered were antivirals, antiinflammatories, antibiotics, antihypertensives, and gastroprotectives. We also computed the costs of laboratory tests and imaging studies performed during hospitalization. We do not include in our analyses indirect cost because our cohort is mainly hospitalized patients.

Once we had calculated the costs for the three cohorts, we estimated the impact of the COVID-19 pandemic for the period analyzed on the hospital's budget for each cohort. The patients in the SARS-CoV-2-negative cohort were included as they had come to the hospital because they thought they had COVID-19 and would not have come had the pandemic not existed. As these criteria might vary according to the research team, we applied two additional approaches to estimate the total impact.

1) In the first case, we calculated the impact of the pandemic for ER and SARS-CoV-2-positive cohorts only.

2) In the second case, we estimated a false-negative rate of $29 \%$ [7], as the true rate was not available. In other words, we assumed that $29 \%$ of SARS-CoV-2negative patients were actually infected and would have returned to the hospital for care, thereby adding to the costs.

\section{Estimation of the National Level}

Using official data reported for COVID-19-related hospital and ICU stays in Spain in June 2020 [8], we estimated the global impact of COVID-19 on the Spanish health budget using a linear approach. The number of cases for the ER cost analysis was estimated by calculating the ratio of SARS-CoV-2-positive patients to both ER patients (1:3.58) and SARS-CoV-2-negative patients $(1: 1.32)$ at our hospital. 
We evaluated two scenarios: a conservative scenario for which we calculated the costs associated with the official cases reported for Spanish hospitals (113,558 hospital admissions and 11,664 ICU admissions) [8] and a worst-case scenario for which we assumed that $52.2 \%$ of SARS-CoV-2-positive patients would be hospitalized and that $5.9 \%$ of these would require ICU admission [8]. In these cases, the missing values were filled using linear interpolation, giving 115,877 hospital admissions and 14,806 ICU admissions.

\section{Sensitivity analyses}

We performed univariate sensitivity analysis to assess the uncertainty surrounding all the parameters in our study. Considering the potential uncertainty arising from differences in clinical practice across Spain, we estimated and compared ranges of unit costs for seven autonomous communities: Andalusia, the Canary Islands, Cantabria, Catalonia, Madrid, Navarre, and the Basque Country (supplementary material Table S1).

We finally performed a probabilistic sensitivity analysis by bootstrapping individual patient data to obtain the most realistic estimates possible [9]. The bootstrap approach is a non-parametric method that makes no distributional assumptions concerning the statistic in question. Instead, it employs the original data in a resampling exercise in order to give an empirical estimate of the sampling distribution of that estimate keeping the correlations between the costs and effects of our population.

We generated 1500 bootstrap samples for each cohort using the size of the original sample and performing resampling with replacement. For each subsample, we calculated mean costs and budget impacts for the reference hospital and Spain as a whole.

\section{Main assumptions}

1) Personal protective equipment (PPE) costs (which have spiraled during the COVID-19 pandemic) were calculated as hospitalization costs. Indirect costs were not included for the lack of information.

2) Even though PPE and disinfectant costs have increased substantially because of the pandemic, price increases were not contemplated in our analyses.

3) Staff overtime telework outside ordinary working hours, and increased workload in other departments (e.g., laundry services) were not considered.

4) Future cost projections were not calculated, as the COVID-19 sequelae are not yet well known. Individual patient requirements during hospitalization or after discharge were also not contemplated.
5) Even though antibiotics are not recommended as prophylactic agents for COVID-19, they were included in the cost analyses as they are part of the workflow at our hospital.

6) The calculations for ICU costs included unit costs and complete blood count, blood gas analysis, and chest X-ray costs.

Microsoft Excel 2010 was used for analyzing the initial scenario, modelling, bootstrapping, and the sensitivity analysis, while SPSS for Windows 26 (IBM Corp. Released 2010) was used to compare cohorts.

\section{Results}

We evaluated 1602 patients, of whom 1446 fulfilled the inclusion criteria. Their characteristics are summarized in Table 1. Between February 26 and May 21, 2020, 912 patients tested positive for SARS-CoV-2 by RT-PCR. Based on the total catchment population for our hospital $(187,258)$, this corresponds to a rate of 487 cases per 100,000 population.

The total estimated impact of COVID-19 on the hospital's budget for the 86 days analyzed was $€ 15,633,180$. The vast bulk of this spending (94.7\%) was related to the treatment and management of SARS-CoV-2-positive patients admitted to hospital. The mean cost per patient was $€ 10,744$ ( $€ 307$ for the ER cohort, $€ 1710$ for the SARS-CoV-2-negative cohort, $€ 50,132$ for the SARSCoV-2-positive cohort without ICU admission, and $€ 280,956$ for the SARS-CoV-2 positive cohort with ICU admission. The breakdown of costs per cohort is given in Table 2.

The main cost components in the SARS-CoV-2-positive cohort were hospital care and hospitalization, at $€ 14,423,298$ ( $97.4 \%$ of total); laboratory tests, at $€ 177,359$ (1.2\%); imaging tests, at €126,204 (0.9\%); and drugs, at $€ 84,078$ (0.6\%).

ICU stays accounted for $5.3 \%$ of the total cost $(€ 823,415.13)$. This cost corresponded to 9 patients (3.54\% of the SARS-CoV-2-positive cohort) with a mean (SD) stay of 37.8 (12.9) days. ICU care accounted for $5.6 \%$ of the total cost for the overall SARS-CoV-2-positive cohort and $32.6 \%$ of the total cost for the SARSCoV-2-positive cohort with ICU admission. ICU staffing costs were $€ 103,661$ (12.6\%) for physicians and $€ 255,556$ (31.0\%) for nursing staff. The cost of ICU stays for the SARS-CoV-2-positive cohort was $€ 464,199$ (56.4\%).

The most used antiviral treatment was hydroxychloroquine combined with azithromycin, but lopinavir/ritonavir $(€ 4335,43.2 \%)$ and gamma interferon (€3594, 35.8\%) were by far the largest cost components in this drug category. The most expensive treatment was tocilizumab $(€ 27,213)$. Testing costs were mainly driven by RT-PCR tests $(€ 94,418)$ and procalcitonin $(€ 33,388)$. Imaging 
Table 1 General characteristics of the study population

\begin{tabular}{|c|c|c|c|}
\hline & ER cohort & SARS-CoV-2-positive cohort & SARS-CoV-2-negative cohort \\
\hline Total patients, $n$ & 989 & 265 & 348 \\
\hline$<18$ years old, $\mathrm{n}$ & 111 & 2 & 7 \\
\hline Readmissions, n & - & 9 & 18 \\
\hline Patients included, $\mathrm{N}$ & 878 & 254 & 323 \\
\hline Age, mean (SD) & $49.3(16.2)$ & $68.4(15.9)$ & $70.7(17.9)$ \\
\hline Male, n (\%) & $381(43.4)$ & $139(54.7)$ & $174(53.9)$ \\
\hline Deaths, n (\%) & $3(0.3)$ & $43(16.9)$ & $32(9.9)$ \\
\hline Days of hospitalization, mean (SD) & $1(0.1) *$ & $44.1(4.8)$ & $8.3(1.7)$ \\
\hline Days in ICU, mean (SD) & $0(0.1)$ & $37.8(4.3)$ & $4.7(1.9)$ \\
\hline
\end{tabular}

ER, emergency room; ICU, intensive care unit; SARS-CoV-2, severe acute respiratory syndrome coronavirus 2; SD, standard deviation; ICU, intensive care unit

* Stays of $16 \mathrm{~h}$ or less were classified as medical visits, while longer stays were classified as ER stays

studies, at $€ 238,037$, accounted for just $1.5 \%$ of the total costs for all patients admitted (SARS-CoV-2-positive and -negative).

According to the results of the parametric sensitivity analysis, if the RT-PCR test-negative patients had not been treated, the total impact on the hospital's budget would have been $€ 14,693,256 €$ (€12,980 per patient). Likewise, if we assume a non-false-negative rate, the total cost would have been $€ 19,376,071$ ( $€ 17,117$ per patient).

\section{Estimation of the National Level}

In the conservative scenario, the total estimated impact of the COVID-19 pandemic on the Spanish public health budget was $€ 9375$ million; $1.5 \%$ of this cost corresponded to the ER cohort, $3.0 \%$ to the SARS-CoV-2negative cohort, $63.2 \%$ to the SARS-CoV-2-positive cohort without ICU admission, and $32.3 \%$ to the SARSCoV-2-positive cohort with ICU admission (Table 3). In the worst-case scenario, the total impact was $€ 10,392$ million (€139 million for the ER cohort, €284 million for the SARS-CoV-2-negative cohort, $€ 5809$ million for the SARS-CoV-2-positive cohort without ICU admission, and $€ 4160$ million for the SARS-CoV-2-positive cohort with ICU admission) (Table 3).

At the time of writing (end of June 2020), the pandemic is still going on and the total number of cases, hospitalizations, and ICU admissions continues to rise. Assuming that the total number of hospitalizations remains below 185,000 and ICU admissions remain below 25,000 , the estimated budget impact of the pandemic should remain below $€ 15,000$ million (Table 4).

\section{Sensitivity analysis}

The main sources of cost variation were physician salaries (range, $€ 10,131$ to $€ 11,357 /$ patient), nursing staff salaries $(€ 10,274$ to $€ 11,215 /$ patient), and general stays ( $€ 10,612$ to $€ 10,876 /$ patient). The budget impact ranged from $€ 14,741,399$ to $€ 16,524,924$ for hospitals and from
$€ 15,050,529$ (€10,344/patient) to $€ 16,913,800$ (€11,625/ patient) for regions.

The probabilistic analysis showed that the total median impact of the COVID-19 pandemic on the hospital budget was $€ 15,581,235$ (Fig. 1). By cohort, the median impact was $€ 14,754,694$ for the SARS-CoV-2-positive cohort, $€ 551,592$ for the SARS-CoV-2-negative cohort, and $€ 269,947$ for the ER cohort.

Median per-patients costs in the SARS-CoV-2-positive cohort were $€ 53,373$ for general stays, $€ 3108$ for ICU stays, $€ 692$ for laboratory tests, $€ 497$ for diagnostic tests, and $€ 330$ for drugs. In the SARS-CoV-2-negative cohort, the median per-patient costs were $€ 1098$ for general stays, $€ 346$ for diagnostic tests, $€ 252$ for blood tests, and $€ 13$ for drugs. The median cost per patient in the ER cohort was $€ 307$.

The median estimated impact on the Spanish public health budget was $€ 9357$ million (interquartile range (IQR), $€ 9071$ to $€ 9689$ million) for the conservative scenario and $€ 10,385$ million (IQR, $€ 10,030$ to $€ 10,758$ million) for the worst-case scenario (Fig. 2).

\section{Discussion}

The COVID-19 impact on the Spanish public health budget during the peak of the pandemic ( 86 days), considering direct medical costs only, was estimated at over $€ 9.4$ billion (12.3\% of total public health expenditure) [10]. This is greater than the impact reported for numerous conditions in Spain, such as multiple sclerosis (€1.4 billion) [11], cancer ( $€ 4.8$ billion) [12], and diabetes ( $€ 5.8$ billion) [13]. These figures give a picture of how big the cost of the pandemic has been at its peak in Spain. The overall impact on the healthcare system, however, can be assumed to be even greater, as care provision for other diseases was disrupted during the peak of the pandemic, as occurred in $68 \%$ of countries in Europe [14, 15]. In Spain, for example, the number of percutaneous coronary interventions to treat myocardial infarction fell 
Table 2 Impact on study hospital budget

\begin{tabular}{|c|c|c|c|}
\hline \multicolumn{4}{|l|}{ Cost in $€ 2020$} \\
\hline Items & ER cohort* & SARS-CoV-2-positive cohort & SARS-CoV-2-negative cohort \\
\hline \multicolumn{4}{|l|}{ Diagnostic tests } \\
\hline RT-PCR for SARS-CoV-2 & $47,855.80$ & $25,673.99$ & $20,888,41$ \\
\hline Complete blood count & - & 3745.74 & 1949,48 \\
\hline Laboratory test + & $19,075.58$ & $10,745.74$ & 5574.59 \\
\hline Coagulationt & - & $25,264.79$ & $13,130.77$ \\
\hline Microbiology $\neq$ & - & 169.44 & 1279.36 \\
\hline Blood gas analysis & - & $12,287.42$ & 6606.97 \\
\hline D dimer & - & 8620.25 & 4255.46 \\
\hline C-reactive protein & - & 7481.50 & 3861.00 \\
\hline Ferritin & - & 5758.36 & 3173.56 \\
\hline Procalcitonin & - & $21,370.62$ & $12,017.19$ \\
\hline Troponin & - & $12,613.64$ & 6835.14 \\
\hline Interleukin 6 & & 327.00 & 1918.40 \\
\hline ICU tests & - & $43,775.00$ & 0.00 \\
\hline Total test costs & $66,931.38$ & $177,359.34$ & $81,490.33$ \\
\hline \multicolumn{4}{|l|}{ Drugs } \\
\hline Antivirals & - & $10,034.86$ & 691.36 \\
\hline Corticosteroids & - & 1007.80 & 192.20 \\
\hline Tocilizumab & - & $27,212.75$ & 0.00 \\
\hline Others, anti-inflammatory & - & 5115.51 & 53.44 \\
\hline Low-molecular-weight heparins & - & 6272.06 & 1123.29 \\
\hline Antibiotics§ & - & 2868.16 & 1795.92 \\
\hline Mucolytics & - & 383.74 & 81.40 \\
\hline ACE inhibitors/ARBs & & 64.10 & 18.99 \\
\hline Beta-blockers & - & 29.21 & 8.95 \\
\hline Calcium antagonists & - & 19.88 & 4.38 \\
\hline Alpha-blockers & - & 19.08 & 6.84 \\
\hline Diuretics & - & 7.92 & 1.74 \\
\hline Statins & - & 19.76 & 5.37 \\
\hline Proton pump inhibitors & - & 285.22 & 87.36 \\
\hline Analgesics & - & 219.10 & 44.15 \\
\hline Antithrombotics & - & 0 & 195.52 \\
\hline Drugs in ICU & - & $30,519.30$ & 0.00 \\
\hline Total drug costs & 0.00 & $84,078.45$ & 4310.91 \\
\hline \multicolumn{4}{|l|}{ Imaging tests } \\
\hline Chest X-ray, portable & $36,533.58$ & $73,108.77$ & $26,880.06$ \\
\hline Computed tomography angiography & 0.00 & $53,095.50$ & $84,952.80$ \\
\hline Total imaging costs & $36,533.58$ & $126,204.27$ & $111,832.86$ \\
\hline \multicolumn{4}{|l|}{ Hospitalization } \\
\hline Medical visits & - & $5,933,775.37$ & 1951,26 \\
\hline Nursing hours & - & $6,095,260.01$ & 2004,36 \\
\hline ER stays & $166,492,90$ & - & - \\
\hline Hospitalization stays & - & $1,570,847.58$ & $350,648.36$ \\
\hline
\end{tabular}


Table 2 Impact on study hospital budget (Continued)

\begin{tabular}{llll}
\hline Cost in $€ \mathbf{2 0 2 0}$ & & & \\
\hline Items & ER cohort* & SARS-CoV-2-positive cohort & SARS-CoV-2-negative cohort \\
\hline Medical visits, ICU & - & $103,660.58$ & 0.00 \\
Nursing hours, ICU & - & $255,555.95$ & 0.00 \\
ICU stays§§ & - & $464,198.60$ & 0.00 \\
Total hospitalization costs & $166,492,90$ & $14,423,298.09$ & $354,648.36$ \\
TOTAL & & & $552,282.36$ \\
TOTAL cost & $269,957.86$ & $14,810,940.15$ & 1709.85 \\
Cost / patient & 307.47 & $58,310.79$ &
\end{tabular}

ACE, angiotensin-converting enzyme; ARBs, angiotensin II receptor blockers; ICU, intensive care unit; RT-PCR, real-time polymerase chain reaction; SARS-CoV-2, severe acute respiratory syndrome coronavirus 2

* Emergency room blood tests include complete blood count, biochemical profile, and coagulation test. Drugs are included as general care costs in the ER

** Includes glycemia, cholesterol, triglycerides, potassium, sodium, albumin, total protein, GPT, GOT, GGT, CPK, LDH, calcium, magnesium, phosphate, transferrin, creatinine, urea, and bilirubin

† Includes: prothrombin time, APTT, and fibrinogen

₹ Includes blood culture, sputum culture, and tests for respiratory viruses (adenovirus, coronavirus, Middle Eastern Respiratory Syndrome, metapneumovirus,

rhinovirus, enterovirus, influenza A, influenza B, parainfluenza, respiratory syncytial virus, Bordetella pertussis, Chlamydophila pneumoniae, Mycoplasma pneumoniae) $\S$ Includes amoxicillin/clavulanic acid, vancomycin, ceftriaxone, linezolid, levofloxacin, moxifloxacin, ciprofloxacin, piperacillin/tazobactam, imipenem, meropenem, ertapenem, daptomycin, and ceftoriden

$\S \S$ In the ICU, daily blood test and blood gas analysis

by $40 \%$ during the pandemic [16], increasing future risks and potential costs.

The mean cost estimated for treating a patient with suspected or confirmed COVID-19 at our hospital was $€ 10,744$. While this is lower than the costs of preterm birth, specialized surgical procedures, or treatments for solid cancer, it is higher than those of most procedures in a medium-sized hospital such as ours, where treating a patient with septicemia requiring mechanical ventilation for more than $96 \mathrm{~h}$, for example, costs $€ 9087$.

Our budget impact analysis of the COVID-19 pandemic in Spain will be a useful tool for hospital and department planning and preparedness purposes. Our findings may also be of help to other countries wishing to forecast the impact of the pandemic on their healthcare systems, although this would require adaptation to local procedures and costs. Cost-estimation studies are also needed to document the investment and use of public funds during the pandemic. Our estimates could also help healthcare authorities and governments design mitigation plans to protect the healthcare system and prevent staff burnout. Disease prevention is increasingly crucial for ensuring the well-being of both society and the economy.

Although our hospital was equipped with additional ICU beds during the initial phase of the pandemic, these were insufficient to meet all our mechanical ventilation needs, meaning that some patients needed to be transferred to other hospitals. We therefore performed a sensitivity analysis in which we varied the percentage of

Table 3 Impact on Spanish public health budget

\begin{tabular}{|c|c|c|c|}
\hline Cohort & No. of patients & Mean cost per patient & $\begin{array}{l}\text { Budget impact } \\
\text { ( } € \text { million) }\end{array}$ \\
\hline \multicolumn{4}{|l|}{ Conservative scenario } \\
\hline ER cohort & 432,854 & $€ 307.47$ & $€ 133.09$ \\
\hline SARS-CoV-2-negative cohort & 159,239 & $€ 1709.85$ & $€ 272.28$ \\
\hline SARS-CoV-2-positive cohort without ICU stay & 113,558 & $€ 50,131.99$ & $€ 5692.89$ \\
\hline SARS-CoV-2-positive cohort with ICU stay & 11,664 & $€ 280,955.81$ & $€ 3277.07$ \\
\hline TOTAL & & & $€ 9375.32$ \\
\hline \multicolumn{4}{|l|}{ Worst-case scenario } \\
\hline ER cohort & 451,730 & $€ 307.47$ & $€ 138.89$ \\
\hline SARS-CoV-2-negative cohort & 166,183 & $€ 1709.85$ & $€ 284.15$ \\
\hline SARS-CoV-2-positive cohort without ICU stay & 115,877 & $€ 50,131.99$ & $€ 5809.14$ \\
\hline SARS-CoV-2-positive cohort with ICU stay & 14,806 & $€ 280,955.81$ & $€ 4159.82$ \\
\hline TOTAL & & & $€ 10,391.99$ \\
\hline
\end{tabular}




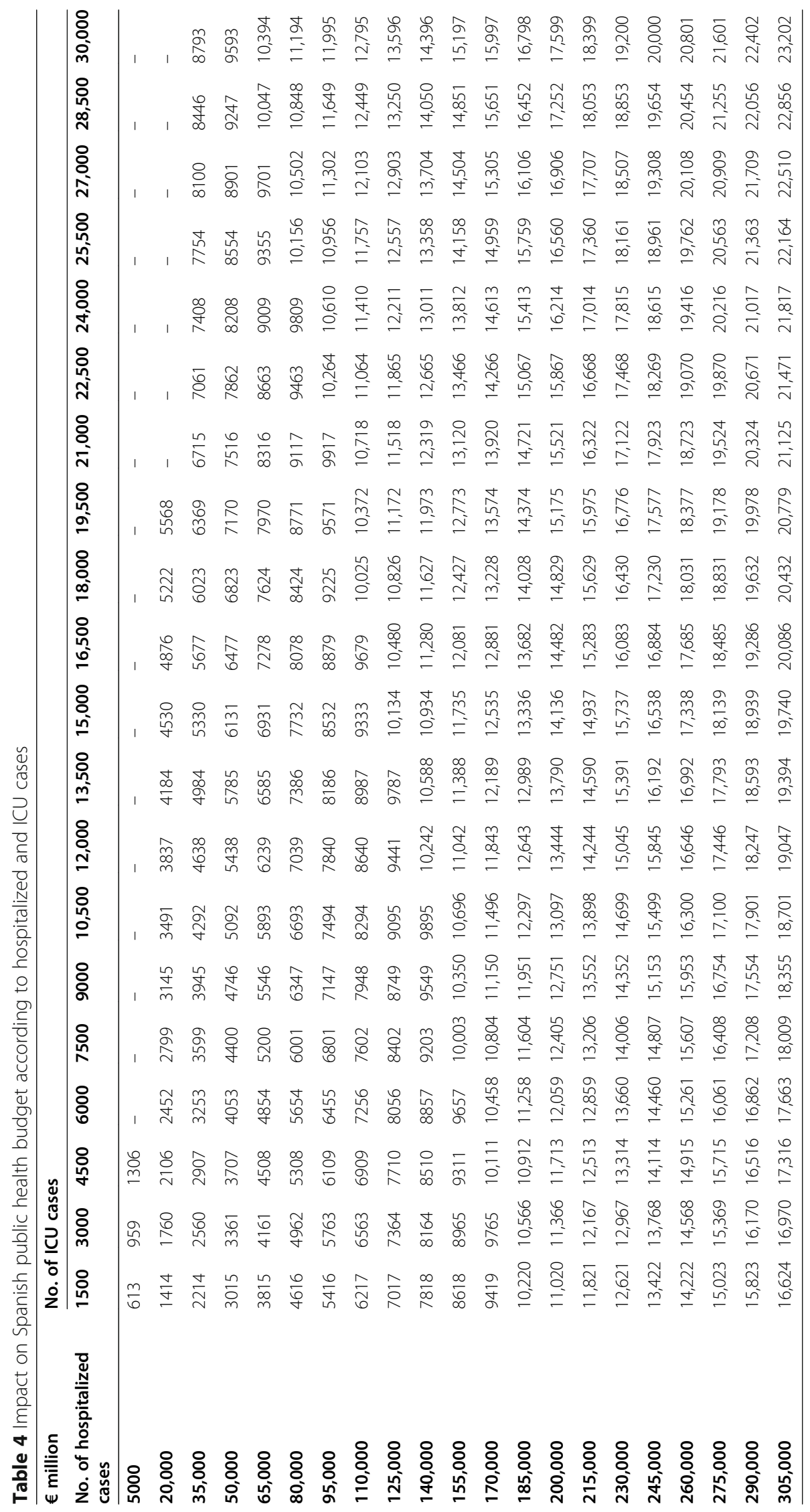




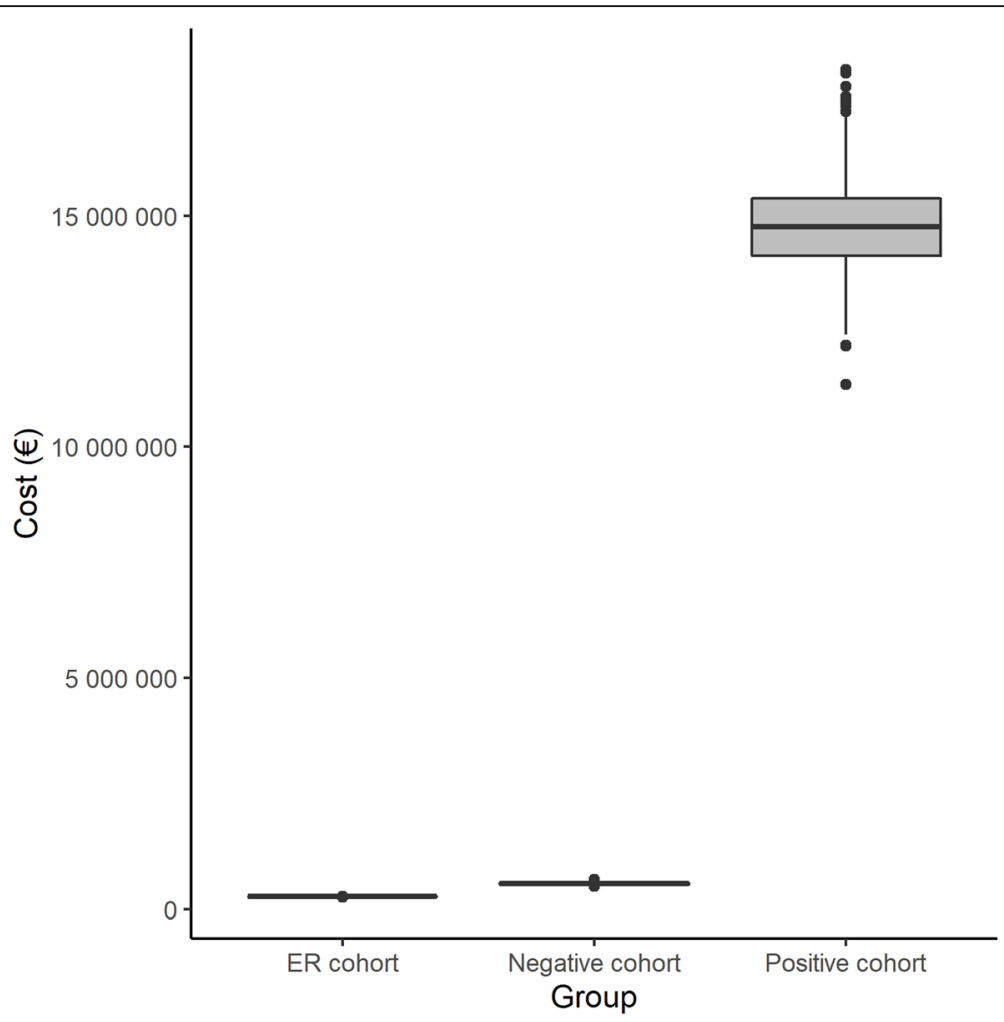

Fig. 1 Sensitivity analysis of the economic impact overall and by cohort (bootstrapping method). SARS-CoV-2, severe acute respiratory syndrome coronavirus 2

patients admitted to the ICU based on data from other published cohorts (10.2\%) [8]. The results showed an increase in cost per patient from $€ 10,744$ to $€ 13,411$. ICU stays accounted for $5.6 \%$ of total costs, even though just $3.5 \%$ of patients required ICU care. The main drivers of costs were staff salaries and general and ICU stays (97.8\%). Drug treatments accounted for just $0.6 \%$ of total costs and can therefore be considered a relatively small cost component.

Using a prediction model for prolonged hospital stays among patients with COVID-19 in China, Hong et al. [17] estimated a mean cost per patient of $€ 925$ (IQR, $€ 636$ to $€ 1395$ ), which is 11.6 times lower than the figure calculated in our study. This difference could be due to the relatively small sample size analyzed by Hong et al. and the exclusion of patients with severe disease. In addition, the study was not a formal cost-analysis study. Another recent Chinese study of 70 patients hospitalized for a median of 16 days (IQR, 10-20 days) estimated a cost of $\$ 6827$ per episode of COVID-19 [18], which is closer to our figure. Nonetheless, the median length of stay for SARS-CoV-2-positive patients in our series was just 8 days (IQR, $5-15$ days) but the cost per patient was much higher, at $€ 50,132$. This difference can largely be attributed to staff costs, as our study was performed during the peak of the pandemic, when the hospital was overstretched. Other possible reasons include cultural differences and differences in healthcare system organization and costs. A US study that developed a Monte Carlo simulation model based on the assumption that $80 \%$ of the population would become infected calculated a total median direct medical cost of $\$ 654$ billion (95\% CI: 615.8-692.8) [19], with a median cost of \$14,366 (95\% CI: 13,545-15,129) per hospitalized patient and $\$ 215$ million (95\% CI: 209-221) for symptomatic patients. Our study, however, is based on real-world data and is not comparable.

To date, two Spanish studies have been published. Rodríguez-Gonzalez et al. [20] performed a cost analysis in a referral hospital $(n=1255)$ with global costs $(€ 0.44$ million per 1000 hospitalized patient and $€ 408$ per patient) similar to our results ( $€ 307$ per patient). These differences may be due to the higher incidence in Madrid during the first wave of COVID-19. However, we also present an estimate of the budgetary impact on the national health system of $€ 9357$ million, by carrying out a probabilistic sensitivity analysis that took into account different incidence scenarios of the disease. In the 


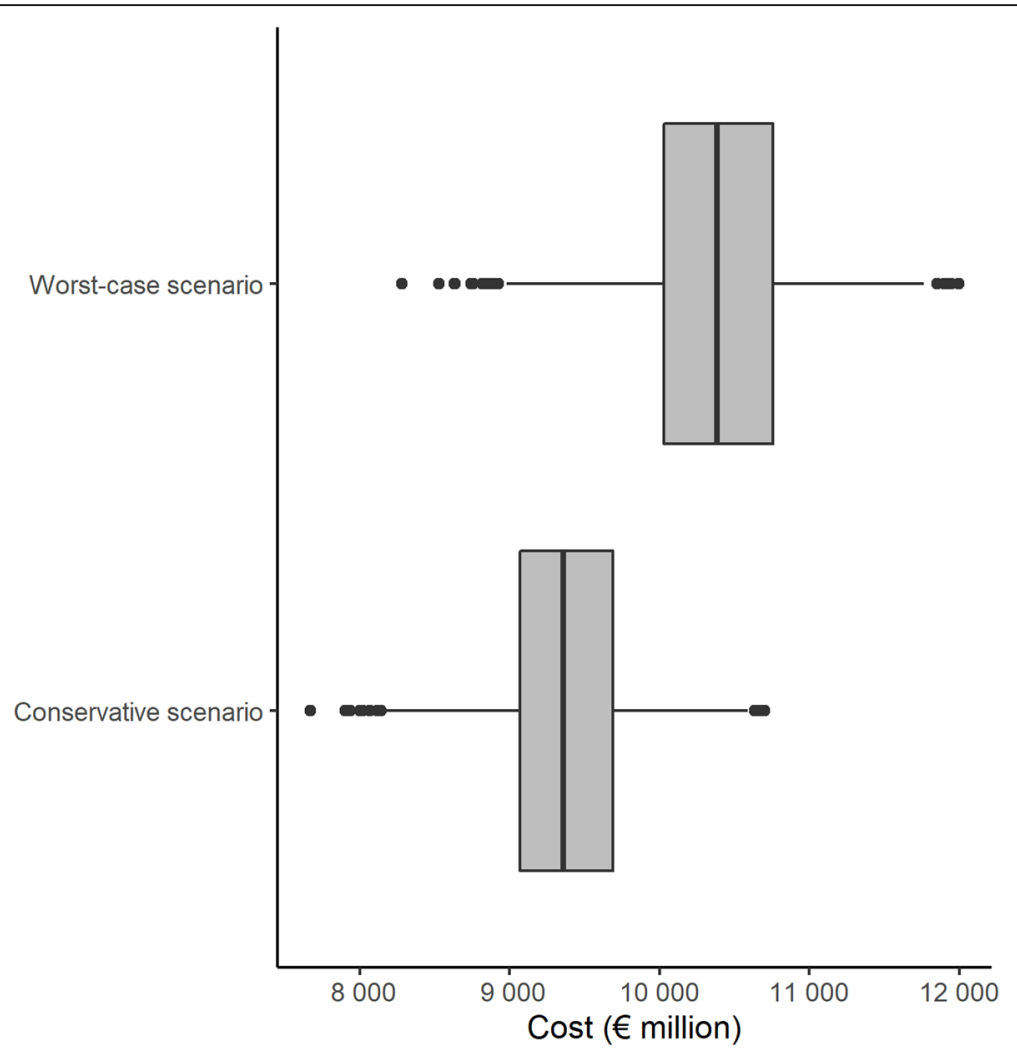

Fig. 2 Impact of COVID-19 pandemic on the Spanish public health budget (bootstrapping method)

second study [21] they make a totally theoretical estimate based on gross domestic product and not on real data like us.

Retrospective cohort studies are prone to selection bias. In an attempt to minimize this risk, we included all patients with suspected SARS-CoV-2 infection who visited the ER at our hospital. One notable strength of our study is the use of individual-level data for both diagnostic tests and treatments.

Another limitation of our study is related to possible false-negative misclassifications. False-negative rates ranging from 16 to $66 \%$ have been reported for RT-PCR, although these have improved over time [7, 22]. The prevalence of SARS-CoV-2 infection also varies by region, although the mean age and sex of hospitalized patients in our cohort were similar to those reported at the national level (66 years and 55\% males for general-stay patients and 63 years and $55 \%$ males for ICU patients) [8]. The main limitation of our study, however, is that our calculations are based on data from a single hospital and cannot therefore be generalized to hospitals with other characteristics. Furthermore, to calculate the national costs, we assumed a constant ratio between negative and positive cohorts. Although, we analyzed the uncertainty of this parameter in the sensitivity analysis, readers must take attention that this relationship might not be linear.

Finally, we did not analyze indirect costs, such as productivity loss, but as most of the patients in the cohort were elderly and healthcare provider perspective.

\section{Conclusions}

The total estimated impact of COVID-19 on our hospital's budget for a period of 86 days during the peak of the pandemic was $€ 15.6$ million, or $€ 10,744$ per patient. On extrapolating these estimates to Spain as a whole, the total direct medical cost accrued up to the end of June 2020 is $€ 10.4$ billion.

\section{Abbreviations}

COVID-19: Coronavirus disease 2019; SARS-CoV-2: Severe acute respiratory syndrome coronavirus 2; AEMPS: Spanish Agency of Medicines and Medical Products; ER: hospital's emergency room; RT-PCR: real-time polymerase chain reaction; ICU: Intensive Care Unit; €: Euros; PPE: Personal protective equipment; IQR: interquartile range

\section{Supplementary Information}

The online version contains supplementary material available at https://doi. org/10.1186/s13561-021-00340-0.

Additional file 1: Table S1. Unit cost for seven autonomous communities. 


\section{Acknowledgments}

To Mrs. Anne Murray for her support to translate the manuscript. This article is part of the doctoral thesis of Laura Álvarez as part of the Doctoral Program in Pharmacy, Granada University (Spain).

\section{Authors'contributions}

Dr. Carrera and R Martínez-Gonzalbez had full access to all the data in the study and are responsible for the integrity of the data and the accuracy of the analysis. Dr. Vazquez checked all data. Laura Alvarez and Dr. Poquet contributed to the publication process control Concept and design: Dr. Carrera y Dr. Martínez promoted the study; and Dr. Vazquez, Dr. Crespo, and Dr. Carrera designed it. Acquisition, analysis, or interpretation of data: Dr. Carrera, R Martínez-Gonzalbez, Dr. Vázquez, Dr. El-Qutob, MA Ramón-Barrios, and Dr. Crespo. Drafting of the manuscript: The first draft of the manuscript was written by Javier Carrera and Laura Alvarez; and revised by Dr. Martínez, Dr. Crespo, MA Ramon Barrios, Dr. El-Qutob, and Dr. Poquet. The last version was written and corrected by Dr. Carrera, Dr. Vazquez, Dr. Crespo, Dr. Poveda and Laura Alvarez. Critical revision of the manuscript for important intellectual content: All authors had revised and approved last version of this manuscript. Statistical analysis: Modelling: Dr. Carrera, Dr. Crespo; Statistical and data managament: Dr. Vázquez, Dr. Carrera, and R Martínez-Gonzalbez. Funding: Dr. Poquet and Dr. Martinez. Administrative, technical, or material support: All authors

\section{Funding}

The authors did not receive support from any organization for the submitted work.

\section{Availability of data and materials}

The data that support the findings of this study are available on request from the corresponding author.

\section{Declarations}

\section{Ethics approval and consent to participate}

The study was registered with the Spanish Agency of Medicines and Medical Products (AEMPS) and approved by the hospital's ethics committee. Verbal informed consent was obtained from all patients and noted in the patients' medical records. This procedure was authorized by the Spanish Health authorities in view of the exceptional epidemiological situation.

\section{Consent for publication}

The work described has not been published previously, is not under consideration for publication elsewhere and, if accepted, will not be published elsewhere without the written consent of the copyright-holder. Its publication is approved by all authors and tacitly or explicitly by the responsible authorities.

\section{Competing interests}

Dr. Crespo received grant or personal fees outside the submitted work from Novartis, Pfizer, Abbvie, Gebro, Takeda, Shire, Mundipharma, Almirall, Boston Scientific, Dexcom, Hospital Clinic of Barcelona and GlaxoSmithKline. The other authors declare that they have not conflict of interest.

\section{Author details}

${ }^{1}$ Pharmacy Service, University Hospital La Plana, Carretera de Vila-real a Burriana, Km. 0.5, 12540 Villarreal, Castellón, Spain. ²Pharmacy Doctoral Program at University of Granada, Granada, Spain. ${ }^{3}$ Pharmacy Service, Hospital de Denia (Marina Salud), Denia (Alicante), Spain. ${ }^{4}$ Ophtalmology Department, Hospital Virxe da Xunqueira, Cee (A Coruña), Spain. ${ }^{5}$ Informatics and computer Service, University Hospital La Plana, Villarreal (Castelló), Spain. ${ }^{6}$ Allergy Service, University Hospital La Plana, Villarreal (Castelló), Spain. ${ }^{7}$ Internal Medicine Unit, University Hospital Doctor Peset, Valencia, Spain. ${ }^{8}$ Grupo Investigación de Atención Farmacéutica, Pharmacy and Pharmaceutical Technology Department, University of Granada, Granada, Spain. ${ }^{9}$ Pharmacy Department, Hospital Universitari i Politecnic La Fe, Valencia, Spain. ${ }^{10}$ Department G.M. statistics, University of Barcelona, Barcelona, Spain. ${ }^{11}$ Axentiva Solutions, Barcelona, Spain.
Received: 13 June 2021 Accepted: 29 September 2021

Published online: 03 November 2021

\section{References}

1. Home - Johns Hopkins Coronavirus Resource Center [Internet]. Available from: https://coronavirus.jhu.edu/ Accessed 30 January 2021.

2. Alfano V, Ercolano S. The efficacy of lockdown against COVID-19: a crosscountry panel analysis. Appl Health Econ Health Policy. 2020;4(4):509-17. https://doi.org/10.1007/s40258-020-00596-3.

3. Yamin M. Counting the cost of COVID-19. Int J Inf Technol. 2020;13:1-7. https://doi.org/10.1007/s41870-020-00466-0.

4. Kabir M, Afzal MS, Khan A, Ahmed H. COVID-19 economic cost; impact on forcibly displaced people. Travel Med Infect Dis. 2020;35:101661. https://doi. org/10.1016/j.tmaid.2020.101661.

5. Teasdale B, Schulman KA. Are U.S. Hospitals still "recession-proof"? [published online ahead of print, 2020 Jul 1]. N Engl J Med (2020); https:// doi.org/10.1056/NEJMp2018846, 383, 13, e82.

6. ACUERDO de 8 de noviembre de 2019, del Consell, por el cual se autorizan determinadas transferencias de crédito para la aplicación del incremento retributivo previsto en el Real decreto ley 24/2018, de 21 de diciembre, por importe global de 9.650.760,22 euros. Expediente 06.001/19-001 (II parte). [2019/10711] [Internet]. Available from: http://www.dogv.gva.es/portal/ ficha_disposicion.jsp?L=1\&sig=009701\%2F2019 Accessed 30 January 2021.

7. Arevalo-Rodriguez I, Buitrago-Garcia D, Simancas-Racines D, ZambranoAchig P, del Campo R, Ciapponi A, et al. False-negative results of initial RTPCR assays for COVID-19: a systematic review. PLoS One. 2020) https://doi. org/;15(12):e0242958. https://doi.org/10.1371/journal.pone.0242958.

8. [Update $n^{\circ} 153$. Coronavirus disease (COVID-19). [Internet]. Available from: https://www.mscbs.gob.es/en/profesionales/saludPublica/ccayes/alertasA ctual/nCov-China/documentos/Actualizacion_153_COVID-19.pdf Accessed 1 July 2020.

9. Tibshirani EB. Introd bootstrap Chaprnan hall N Y EEUU; 1993.

10. Ministerio de Sanidad, Consumo y Bienestar Social - Portal Estadístico del SNS - Informe anual del Sistema Nacional de Salud [Internet]. Available from: https://www.mscbs.gob.es/estadEstudios/estadisticas/sisInfSanSNS/ta blasEstadisticas/InfAnSNS.htm.

11. Fernández O, Calleja-Hernández MA, Meca-Lallana J, Oreja-Guevara C Polanco A, Pérez-Alcántara F. Estimate of the cost of multiple sclerosis in Spain by literature review. Expert Rev Pharmacoecon Outcomes Res. 2017) https://doi.org/10.1080/14737167.2017.1358617;17(4):321-33.

12. Badía X, Tort M, Manganelli AG, Camps C, Díaz-Rubio E. The burden of cancer in Spain. Clin Transl Oncol. 2019;21(6):729-34. https://doi.org/10.1 007/s12094-018-1972-7.

13. Crespo C, Brosa M, Soria-Juan A, López-Alba A, López-Martínez N, Soria B. Direct cost of diabetes mellitus and its complications in Spain (SECCAID study: Spain estimated cost Ciberdem-Cabimer in diabetes). Avances en Diabetologia. 2013) https://doi.org/10.1016/j.avdiab.2013.07.007;29(6):182-9.

14. WHO/Europe $\mid$ Regional Director - Statement - Preparing for the autumn is a priority now at the WHO Regional Office for Europe [Internet]. Available from: https://www.euro.who.int/en/about-us/regional-director/statements/ statement-preparing-for-the-autumn-is-a-priority-now-at-the-who-regionaloffice-for-europe. Accessed 1 July 2020.

15. Roffi M, Capodanno D, Windecker S, Baumbach A, Dudek D. Impact of the COVID-19 pandemic on interventional cardiology practice: results of the EAPCI survey. Eurolntervention. 2020) https://doi.org/10.4244/EIJ-D-20-00528; 16(3):247-50.

16. Rodriguez-Leor O, Cid-Alvarez B, Ojeda S. Impact of the COVID-19 pandemic on care activity in interventional cardiology in Spain. REC Interv Cardiol. 2020; https://doi.org/10.24875/RECICE.M20000123.

17. Hong Y, Wu X, Qu J, Gao Y, Chen H, Zhang Z. Clinical characteristics of coronavirus disease 2019 and development of a prediction model for prolonged hospital length of stay. Ann Transl Med. 2020) https://doi.org/1 0.21037/atm.2020.03.147;8(7):443.

18. Li XZ, Jin F, Zhang JG, Deng YF, Shu W, Qin JM, et al. Treatment of coronavirus disease 2019 in Shandong, China: a cost and affordability analysis. Infect Dis Poverty. 2020) https://doi.org/10.1186/s40249-020-00689$0 ; 9(1): 78$.

19. Bartsch SM, Ferguson MC, McKinnell JA, et al. The potential health care costs and resource use associated with COVID-19 in the United States. Health Aff (Millwood). 2020) https://doi.org/10.1377/hlthaff.2020.00426:39(6): 927-35. 
20. Rodriguez-Gonzalez CG, Chamorro-de-Vega E, Valerio M, Amor-Garcia MA, Tejerina F, Sancho-Gonzalez M, et al. COVID-19 in hospitalised patients in Spain: a cohort study in Madrid. Int J Antimicrob Agents. 2021;57(2):106249. https://doi.org/10.1016/j.ijantimicag.2020.106249.

21. González-López-Valcárcel B. Vallejo-Torres, Laura. The costs of COVID-19 and the cost-effectiveness of testing. Applied Economic Analysis. 2021;29(85):7789. https://doi.org/10.1108/AEA-11-2020-0162.

22. Woloshin S, Patel N, Kesselheim AS. False negative tests for SARS-CoV-2 infection —challenges and implications. N Engl J Med. 2020) https://doi. org/10.1056/NEJMp2015897;383(6):e38.

\section{Publisher's Note}

Springer Nature remains neutral with regard to jurisdictional claims in published maps and institutional affiliations.

Ready to submit your research? Choose BMC and benefit from:

- fast, convenient online submission

- thorough peer review by experienced researchers in your field

- rapid publication on acceptance

- support for research data, including large and complex data types

- gold Open Access which fosters wider collaboration and increased citations

- maximum visibility for your research: over $100 \mathrm{M}$ website views per year

At $\mathrm{BMC}$, research is always in progress.

Learn more biomedcentral.com/submissions 